\title{
Prevalence of Dry Mouth and Associated Demographic, Behavioral and Clinical Factors: A Hospital-based Study among the Elderly in Dar Es Salaam
}

\author{
Anna Joseph Lyimo, Makoye Mang'oma Ndalahwa and Irene Kida Minja
}

\section{ABSTRACT}

\begin{abstract}
Aim: This study aimed at determining the prevalence of self-reported and clinically determined dry mouth among elderly patients attending a referral hospital in Dar es Salaam; and to assess factors associated with the condition.
\end{abstract}

Methodology: This cross-sectional study included elderly patients aged 60 years and above who were attending Mwananyamala referral hospital in Dar es Salaam between January and February 2017. Data was collected using structured interview questionnaire, followed by clinical oral examination. Chi-square test was used to check for bivariate associations between variables; and multiple logistic regressions to determine relative contribution of demographic, behavioral and clinical variables on dry mouth.

Results: Information was obtained from a total number of 334 elderly patients aged $60-90$ years, response rate $86 \%$. The prevalence of selfreported dry mouth (xerostomia) was $65.3 \%$ and clinically determined dry mouth $64.1 \%$. Multiple logistic regression analyses revealed that elderly participants who were 70+ years old $(O R=2.0, C I=1.1-3.6$ and $O R=2.5$, $C I=1.5-4.4)$; those who used tobacco $(O R=2.1 ; C . I=1.2-3.5$ and $O R=2.9$; $C I=1.5-5.6$, ; those having at least one tooth with cervical caries $(O R=1.7$, $C I=1.0-2.9$ and $O R=2.9 ; C . I=1.7-5.1)$ and poor oral hygiene $(O R=2.7$; C.I=1.6-4.5 and $O R=4.3$; $C . I=2.5-7.3$ ) were significantly at higher odds for xerostomia and clinically determined dry mouth, respectively. Level of education, systemic disease, and use of systemic medication showed no statistically significantly association with dry mouth i.e xerostomia and clinically determined dry mouth.

Conclusions: The results of this study revealed that, the prevalence of complaints of xerostomia and clinically determined dry mouth were high among elderly patients attending Mwananyamala referral hospital. The condition was significantly associated with socio demographic, clinical and behavioral factors showing the need for multi-disciplinary oral health care for this group of population.

Keywords: dry mouth, elderly, Tanzania, xerostomia.
Published Online: December 28, 2020

ISSN: 2593-8339

DOI: $10.24018 /$ ejmed.2020.2.6.617

Anna Joseph Lyimo

Dental Department, Muhimbili National

Hospital, Dar es Salaam, Tanzania.

(e-mail:

drannalyimomchomba@gmail.com)

\section{Makoye Mang'oma Ndalahwa}

Restorative Dentistry Department,

Muhimbili University of Health and Allied Sciences, Dar es Salaam, Tanzania.

(e-mail: mndalahwa@yahoo.co.uk)

\section{Irene Kida Minja*}

Restorative Dentistry Department,

Muhimbili University of Health and Allied Sciences, Dar es Salaam, Tanzania.

(e-mail: ikminja@muhas.ac.tz)

*Corresponding Author

\section{INTRODUCTION}

With the gradual change in global demographic pattern, an increase in the proportion of elderly is expected, especially in low- and middle-income countries like Tanzania [1]. Elderly people are at risk of non-communicable diseases, this poses increased burden when it comes to their need for health and oral health care in countries were communicable diseases are still prevalent [2]. Whereas hyposalivation indicates an objectively determined reduced salivary flow rate, xerostomia is a subjective feeling of dry mouth reported by patient through answering a set of structured questions [3]. Dry mouth may either be caused by diseases which directly affect the salivary glands, e.g. Sjögren syndrome, or indirect effects, such as presence of systemic diseases and their treatment and behavioral factors e.g. tobacco use. Presence of dry mouth may bring about complications that include high rates of plaque, periodontal problems and caries, due to lack of wash out effect [4]. Presence of such complications may interfere with normal oral function and hence affect their quality of life [5], [6].

The most recent review and meta-analysis on prevalence of dry mouth revealed rates ranging from $0.01 \%$ to $45 \%$ for xerostomia and $0.02 \%$ to $40 \%$ for hyposalivation i.e., clinically examined [7]. These studies have mostly been conducted in high income countries. This variation depends on the population being studied i.e. community based versus hospital based; and the instruments or tools utilized. Studies in the African setting are meagre, among these few studies, xerostomia has been reported to affect patients with diabetes 
and populations living with Human Immunodeficiency virus [8], [9].

Elderly population and female have been reported to be the most commonly affected by xerostomia [10]. Similarly, the prevalence of dry mouth whether reported or clinically examined, was observed to be higher among the elderly [11]. The most probable reason cited was due to the fact that majority of the elderly patients either develop systemic diseases or use medications thereof, which increases the odds of complaints of dry mouth as well as dry oral tissues on clinical examination. Tobacco use in different forms for instance cigarette smoking behavior has been seen as one of the factors that pre-dispose to dry mouth [12] as well as change in saliva quality [13].

Due to a dramatic increase in this group of population in Tanzania (URT, household census 2002 and 2012), a deterioration of oral health status and conditions like dry mouth and their complications is anticipated. Before the conduction of this study [14] there was no retrieval data on prevalence of dry mouth in Tanzania. This study, therefore, set out to examine the prevalence of xerostomia and clinically determined dry mouth and their associated factors. This baseline information will assist in formulation of studies that will address oral health of the elderly among representative sample of the elderly in Tanzania.

\section{METHODS}

This cross-sectional study was conducted in Mwananyamala referral hospital, in Dar-es salaam city from January to February 2017. The study included all patients aged 60 years and above attending the elderly general clinics for treatment during the study period. Mentally challenged individual, those who received radiotherapy in head and neck region and those with health condition that could interfere with interview and clinical examination were excluded from the study. All consenting patients were interviewed using structured questions, followed by clinical examination.

Interview schedule was constructed in English, and translated to Kiswahili which is a national and official language, spoken proficiently by most (95\%) of Tanzanians. Face-to-face interview was conducted by one trained and calibrated dentist (AJL) in an allocated room in a private setting. The structured interview schedule included questions on elderly patients' social-demographic details (age, sex and level of education), behavioral factors (smoking and tooth brushing habits), reported history of systemic disease and use of systemic medications. To assess xerostomia, a set of questions developed by Fox et al., (1987) was used, see appendix 1. A total score of the 10 xerostomia items, ranging from 0 to 10 , was obtained and later on the score was dichotomized into two $0=$ 'no report of symptom' and $1=$ 'report of at least one symptom' [14].

After the interview, one trained and calibrated dentist (AJL) conducted all clinical oral examinations using day light as a source of illumination at the dental clinic, with an assistant recording the observations. Mouth mirrors and sickle probe (No. 23 explorer) were used to conduct oral clinical examination. Dry mouth was assessed clinically by recording whether or not a mouth mirror 'sticks to the buccal mucosa'. Participants were said to have 'dry mouth' if the mirror sticks to the buccal mucosa. Oral hygiene of elderly patients was assessed using the Mucosal - Plaque Score (MPS) [15]. The index consists of four-point mucosal score and four-point plaque score which are added to get MPS. Further to this, the participants were examined for presence of prothesis of any type as well as cervical caries on any tooth. Participants who were identified with problems that needed treatment were referred for treatment from the dental clinic in the hospital. Furthermore, all participants were provided with oral health education

Statistical Package for Social Sciences (SPSS) for PC, version 23.0, (IBM corporation, Armonk, NY, USA) was used to analyze data. Cross tabulations were done to assess bivariate relationship between the measures of dry mouth (perceived and clinically determined dry mouth) with sociodemographics, clinical factors and reported oral health behaviors, using Pearson's chi-square statistical tests. Significant level was set at $\mathrm{p}<0.05$. Factors associated with xerostomia and clinically determined dry mouth were assessed by Multiple logistic regression analysis, using the logit model with $95 \%$ confidence interval and odds ratios, indicating statistically significant relationship if both values were above or below 1 .

The study was granted ethical approval by the Research Ethics Committee of the Muhimbili University of Health and Allied Sciences (MUHAS) and permission to conduct the study was obtained from Mwananyamala Referral Hospital Administration. Informed consents were obtained from the participants before interview and clinical examination.

\section{RESULTS}

A total of 334 elderly patients were interviewed and clinically examined. The mean age of participants was 67.7 years SD 6.6 ranging from 60 to 90 years. Majority of the elderly participants belonged to the age group 60-69 $(74.9 \%$; $\mathrm{n}=250)$, female $(55.4 \% ; \mathrm{n}=185)$ and have completed primary education $(65.3 \% ; n=218)$. Almost all patients reported to brush their teeth, while less than half of them $(40.1 \% ; n=134)$ reported to use tobacco of different forms (Table1). Clinical examination findings revealed that more than a half of the elderly had cervical caries $(56.6 \% ; n=189))$ and poor oral hygiene $(52.1 \% ; n=74))$, while only $14 \%(n=47)$ of them had prosthesis of different forms. Almost all the participants reported to have been diagnosed with systemic disease (94.6\%: $n=316)$ with about $76.6 \%(n=256)$ of them reporting to use systemic medications (Table 1).

Prevalence of reported dry mouth (xerostomia) was $65.3 \%$ $(n=218)$, while the number of patients who were clinically observed to have dry mouth was $64.1 \%(n=214)$. There were 184 patients $55.1 \%$ who were found to have both xerostomia and clinically observed to have dry mouth.

As depicted in Table 2, on bivariate analysis, age (p-values 0.004 and 0.000 ), tobacco use (p-values 0.001 and 0.000 ), having cervical caries (p-values 0.000 and 0.000 ) and oral hygiene (p-values 0.000 and 0.000 ) variables showed significant association with both self-reported (xerostomia) and clinically determined dry mouth, respectively. Whereas use of systemic medication was statistically significantly 
associated with clinically determined dry mouth ( $\mathrm{p}$-value 0.004), the association was not observed in xerostomia. Furthermore, sex, education, tooth brushing, presence of prosthesis and systemic disease did not significantly associate with self-reported (xerostomia) and clinically determined dry mouth.

TABLE 1: FREQUENCY DistribUTION OF ELDERLY PARTICIPANT'S SOCIODEMOGRAPHIC DETAILS, BEHAVIORAL AND CLINICAL CHARACTERISTICS

\begin{tabular}{lcc}
\multicolumn{1}{c}{$(\mathrm{N}=334)$} & & \\
\hline \multicolumn{1}{c}{ Socio-demographic characteristics } & $\mathbf{N}$ & $\%$ \\
\hline Age & & \\
60-69 years & 250 & 74.9 \\
70+ years & 84 & 25.1 \\
Sex & 149 & 44.6 \\
Male & 185 & 55.4 \\
Female & 116 & 34.7 \\
Level of education: No primary education & 218 & 65.3 \\
Completed 1 education \& above & & \\
Behavioural characteristics & 134 & 40.1 \\
Tobacco use: yes & 333 & 99.7 \\
Tooth brushing: yes & & \\
Clinical indicators & 189 & 56.6 \\
Presence of cervical caries: Yes & 47 & 14.1 \\
Prosthetic status: at least one prosthesis: Yes & 174 & 52.1 \\
Poor oral hygiene status: Yes & 316 & 94.6 \\
Systemic disease: Yes & 256 & 76.6 \\
Use of systemic medication: Yes & & \\
\hline
\end{tabular}

TABLE 2: REPORTED DRY MOUTH AND CLINICALLY DETERMINED ORAL DRYNESS ACCORDING TO SOCIO-DEMOGRAPHIC, BEHAVIORAL AND CliniCAL CHARACTERISTICS. CHI SQUARE ANALYSES

\begin{tabular}{|c|c|c|c|c|c|}
\hline & & \multicolumn{2}{|c|}{ Xerostomia } & \multicolumn{2}{|c|}{$\begin{array}{c}\text { Clinically determined } \\
\text { dry mouth }\end{array}$} \\
\hline & & Yes \% (n) & $\begin{array}{c}\mathrm{p}- \\
\text { value }\end{array}$ & Yes \% (n) & $\mathrm{p}$-value \\
\hline \multirow[t]{2}{*}{ Age (years) } & $60-69$ & $61.2(153)$ & 0.007 & $58.4(146)$ & $0.000^{* *}$ \\
\hline & $70+$ & $77.4(65)$ & & $81.0(68)$ & \\
\hline \multirow[t]{2}{*}{ Sex } & Male & $68.5(102)$ & 0.272 & $64.4(96)$ & 0.903 \\
\hline & Female & $62.7(116)$ & & $63.8(118)$ & \\
\hline \multirow[t]{2}{*}{ Education } & None & $62.1(72)$ & 0.399 & $57.8(67)$ & 0.94 \\
\hline & $\geq 1^{\circ}$ educ & $67.0(146)$ & & $67.4(147)$ & \\
\hline \multirow{2}{*}{$\begin{array}{c}\text { Tobacco } \\
\text { use }\end{array}$} & Yes & 76.1 (102) & 0.001 & 76.9 (103) & $0.000 * *$ \\
\hline & No & $58.0(116)$ & & $55.5(111)$ & \\
\hline \multirow{2}{*}{$\begin{array}{c}\text { Tooth } \\
\text { brushing }\end{array}$} & Yes & $65.2(217)$ & 0.465 & $64.0(213)$ & \\
\hline & No & $100(1)$ & 0.405 & $100(1)$ & 0.453 \\
\hline \multirow{2}{*}{$\begin{array}{c}\text { Cervical } \\
\text { caries }\end{array}$} & Yes & $74.6(141)$ & & 78.8 (149) & \\
\hline & No & $53.1(77)$ & 0.000 & $44.8(65)$ & 0.000 \\
\hline \multirow{2}{*}{$\begin{array}{l}\text { Presence of } \\
\text { prosthesis }\end{array}$} & Yes & $76.6(36)$ & 0790 & $80.9(38)$ & 0.100 \\
\hline & No & $63.4(184)$ & 0.190 & $61.3(176)$ & 0.100 \\
\hline \multirow{2}{*}{$\begin{array}{c}\text { Oral } \\
\text { hygiene } \\
\text { status }\end{array}$} & Poor & 78.7 (137) & & $82.8(144)$ & \\
\hline & Good & $50.6(81)$ & 0.000 & $43.8(70)$ & $0.000 * *$ \\
\hline \multirow{2}{*}{$\begin{array}{c}\text { Presence of } \\
\text { systemic } \\
\text { disease }\end{array}$} & Yes & $64.9(205)$ & & $64.6(204)$ & \\
\hline & No & $72.2(13)$ & 0.524 & $55.6(10)$ & 0.439 \\
\hline $\begin{array}{l}\text { Systemic } \\
\text { medication }\end{array}$ & $\begin{array}{l}\text { Yes } \\
\text { No }\end{array}$ & $\begin{array}{c}66.8(171) \\
60.3(47) \\
\end{array}$ & 0.288 & $\begin{array}{c}66.8(171) \\
55.1(43)\end{array}$ & $0.041 *$ \\
\hline
\end{tabular}

Variables included in multivariate model were those that showed statistical significance when subjected to Chi-square statistics (Table 3). Elderly in the age group of 70 and above were more likely to have xerostomia and clinically determined dry mouth $(\mathrm{OR}=2.0, \mathrm{CI}=1.1-3.6$ and $\mathrm{OR}=2.5$, $\mathrm{CI}=1.5-4.4$, respectively) than those aged 60-69 years. Similarly, elderly patients who used tobacco were at higher odds of having xerostomia and clinically determined dry mouth $(\mathrm{OR}=2.1 ; \mathrm{CI}=1.2-3.5$ and $\mathrm{OR}=2.9 ; \mathrm{CI}=1.5-5.6$, respectively) when compared to those who did not use tobacco. Also, those who were clinically observed to have cervical caries were more likely to report xerostomia and clinically observed to have dry mouth $(\mathrm{OR}=1.7, \mathrm{CI}=1.0-2.9$ and $\mathrm{OR}=2.9 ; \mathrm{CI}=1.7-5.1$, respectively) than the elderly who had no cervical caries. Finally, elderly patients who were observed to have poor oral hygiene were significantly at higher odds of having xerostomia and clinically determined dry mouth $(\mathrm{OR}=2.7 ; \mathrm{CI}=1.6-4.5$ and $\mathrm{OR}=4.3 ; \mathrm{CI}=2.5-7.3)$, respectively) than those with good oral hygiene.

TABLE 3: FACTORS ASSOCIATED WITH XEROSTOMIA AND CLINICALLY DETERMined ORAL DRYNESS. CHI SQUARE STATISTICS, OdDS RATIO (OR) AND 95\% CONFIDENCE INTERVAL (CI)

\begin{tabular}{|c|c|c|c|c|c|}
\hline \multirow{2}{*}{ Covariates } & & \multicolumn{2}{|c|}{ Xerostomia } & \multicolumn{2}{|c|}{ Clinical dry mouth } \\
\hline & & $\%(\mathrm{n})$ & OR (CI) & $\%(\mathrm{n})$ & OR (CI) \\
\hline \multirow{2}{*}{$\begin{array}{c}\text { Age } \\
\text { (years) }\end{array}$} & $60-69$ & $61.2(153)$ & 1 & $\begin{array}{c}58.4 \\
(146)\end{array}$ & 1 \\
\hline & $70+$ & $77.4(65)$ & $\begin{array}{c}2.0 \\
(1.1-3.6)^{*}\end{array}$ & $\begin{array}{l}81.0 \\
(68) \\
\end{array}$ & $\begin{array}{c}2.5 \\
(1.5-4.4)^{* *}\end{array}$ \\
\hline \multirow{2}{*}{$\begin{array}{c}\text { Tobacco } \\
\text { use }\end{array}$} & No & $58.0(116)$ & 1 & $\begin{array}{l}55.5 \\
(111)\end{array}$ & 1 \\
\hline & Yes & $76.1(102)$ & $\begin{array}{c}2.1 \\
(1.2-3.5)^{*}\end{array}$ & $\begin{array}{c}76.8 \\
(103) \\
\end{array}$ & $\begin{array}{c}2.9 \\
(1.5-5.6)^{* *}\end{array}$ \\
\hline \multirow{2}{*}{$\begin{array}{c}\text { Cervical } \\
\text { caries }\end{array}$} & No & $53.1(77)$ & 1 & $\begin{array}{l}44.8 \\
(65)\end{array}$ & 1 \\
\hline & Yes & $74.6(141)$ & $\begin{array}{c}1.7 \\
(1.0-2.9)^{*}\end{array}$ & $\begin{array}{c}78.8 \\
(149) \\
\end{array}$ & $\begin{array}{c}2.9 \\
(1.7-5.1)^{* * *}\end{array}$ \\
\hline \multirow{2}{*}{$\begin{array}{c}\text { Oral } \\
\text { hygiene }\end{array}$} & Good & $50.6(81)$ & 1 & $\begin{array}{l}43.8 \\
(70)\end{array}$ & 1 \\
\hline & Poor & 78.7 (137) & $\begin{array}{c}2.7 \\
(1.6-4.5)^{* *}\end{array}$ & $\begin{array}{l}82.8 \\
(144)\end{array}$ & $\begin{array}{c}4.3 \\
(2.5-7.3) * *\end{array}$ \\
\hline
\end{tabular}

Key: $* \mathrm{p}<0.05 ; * * \mathrm{p}<0.01$

\section{DISCUSSION}

In this cross-sectional hospital-based study, the prevalence of xerostomia and clinically assessed dry mouth were high. These finding are similar to what has been reported previously by Carda et al. [16] in their study among elderly patients with type-2-diabetes mellitus. This study being hospital based, could be the reason for such high prevalence, since, most of the participants reported long term use of medication for conditions like diabetes mellitus, hypertensions, and chronic pains. This study did not show significant association of both xerostomia and clinically assessed dry mouth with sex, contrary to the findings reported by Johansson and colleagues among Swedish elderly [11]. Similarly, level of education of the elderly showed no association with the prevalence of xerostomia and clinical oral dryness unlike what has been reported in previous studies that showed dry mouth is associated with people who have lower education [17], The lack of association of sex and education in the current study could be due to the type of population studied having similar socio-economic characteristics which might have masked important aspects associated with dry mouth. The association between age with xerostomia and clinically determined dry mouth is in agreement with previous studies that show an increase in dry mouth with ageing [18]. This finding might be due to senesces and increase in polypharmacy with concurrent agerelated medical conditions [18].

Oral health related behaviors have been reported previously to have effect on dry mouth. Khan and co-workers reported no significant reduction in salivary secretion with smoking [19]. However, other scholars report reduced amount of saliva among participants who used tobacco in different forms, similar to findings in this study among elderly patients in Mwananyamala Hospital [11], [12], [20]. 
While short term effect of tobacco smoking has been seen to increase salivary output, long term use of tobacco could lead to dry mouth as stated previously due to the effects of smokeless tobacco on minor salivary glands causing them to undergo degenerative changes [21]. More investigations are suggested to ascertain the effects of tobacco in dry mouth [22].

Reported toothbrushing, as one of the oral health behaviors examined in the current study, did not show significant association with the reported and clinically determined dry mouth. Contrary to the study done previously among institutionalized elderly in Brazil [23]. Almost all (except one elderly) reported to brush their teeth at once a day. However, despite the high percentage of elderly reporting to brush their teeth, the majority of them were clinically found to have poor oral hygiene (Table 1). These findings are similar to what has been reported in previous survey of older adults in Tanzania [24]. Ineffective tooth brushing, poor technique and lack of assistance to perform proper tooth brushing might have played a role in this finding.

Poor oral hygiene strongly associated with both xerostomia and clinically determined dry mouth. Saliva plays a pivotal role in maintain a healthy oral environment. Hyposalivation has been reported to be associated with high plaque retention similar to what was observed in this study [25]. Lack of sufficient amount and recommended quality of saliva has been reported to be one of the factors that contribute to plaque accumulation, due to absence of cleansing ability of saliva. This lack of cleansing effects of saliva could also explain the observed association of cervical caries with both xerostomia and clinically determined dry mouth in this study.

In this study the proportion of elderly with prosthesis was low, similar to what has been reported before among Tanzanian older adults [26]. On the same note, the relationship between having prosthesis and reported / clinically determined dry mouth was not established, further studies would be needed in order to ascertain the stated previous phenomenon.

Having systemic conditions has been observed to contribute to xerostomia and clinically determined dry mouth, attributed to effects of disease conditions on salivary glands [8]. This association was not observed in this study. Further to this, use of systemic medication has been reported before to be associated with xerostomia and hyposalivation. dry mouth was also reported to increase with increase in the number of systemic medications [6]. In this study, being hospital based, could be the reason for the lack of association as almost all participants had systemic diseases and reported to be using systemic medications. Population based studies are recommended to ascertain this relationship among the Tanzanian population.

The finding from this study should be taken with caution as it utilized a hospital based cross sectional method to assess self-reported complaints of dry mouth, and clinical examination using mouth mirror for reduced saliva. The ideal method should have been longitudinal comparison studies utilizing representative sample from the Tanzanian population. Notwithstanding this, the current findings have provided a picture on prevalence of dry mouth that can used to guide future studies."

\section{CONCLUSION}

The results of this study revealed that, the prevalence of xerostomia and clinically determined dry mouth were high among elderly patients attending Mwananyamala referral hospital. Both xerostomia and clinically observes dry mouth were significantly associated with ageing, tobacco use in different forms as well as poor oral hygiene and presence of cervical caries. The immediate implication obtained from the study shows the need for thorough medical history, dental examination and multi-disciplinary approach to oral health care for this group of population.

\section{ACKNOWLEDGMENT}

The authors would like to acknowledge the local administrative authorities and the Muhimbili University of Health and Allied Sciences (MUHAS) - Research Ethics Committee for giving permission to conduct this study. This study was financially supported by the Muhimbili National Hospital, Dar es Salaam Tanzania.

\section{REFERENCES}

[1] UN. United Nations, Department of Economic and Social Affairs, Population Division (2019). World Population Ageing 2019: Highlights (ST/ESA/SER.A/430). [Internet]. 2019 [cited 2020 Oct 4]. Available from https://www.un.org/en/development/desa/population/publications/pd f/ageing/WorldPopulationAgeing2019-Highlights.pdf.

[2] URT. Strategic Action Plan for Prevention and control of non communicable diseases in Tanzania 2016 - 2020. Minist Heal Community Dev Gender, Elder Child [Internet]. 2016;117. Available from:

https://www.worlddiabetesfoundation.org/sites/default/files/NCD Stategic Plan 2016 - 2020.pdf.

[3] Ying Joanna N Di, Thomson WM. Dry mouth - An overview. Singapore Dent J [Internet]. 2015 Dec [cited 2019 Jun 30];36:12-7. Available from: https://linkinghub.elsevier.com/retrieve/pii/S0377529114200198.

[4] Humphrey S, Williamson R. A review of saliva: normal composition, flow, and function. J Prosthet Dent [Internet]. 2001 [cited 2020 Oct 4];85(2):162-9. Available from: https://www.sciencedirect.com/science/article/pii/S00223913015403 29.

[5] Niklander S, Veas L, Barrera C, Fuentes F, Chiappini G, Marshall M. Risk factors, hyposalivation and impact of xerostomia on oral healthrelated quality of life. Braz Oral Res. 2017;31:e14.

[6] Johansson AK, Johansson A, Unell L, Ekbäck G, Ordell S, Carlsson GE. Self-reported dry mouth in 50- to 80-year-old Swedes: Longitudinal and cross-sectional population studies. J Oral Rehabil. 2020 Feb 1;47(2):246-54.

[7] Agostini BA, Cericato GO, Silveira ER da, Nascimento GG, Costa F dos S, Thomson WM, et al. How Common is Dry Mouth? Systematic Review and Meta-Regression Analysis of Prevalence Estimates. Braz Dent J [Internet]. 2018 Dec [cited 2019 Jun 30];29(6):606-18. Available http://www.scielo.br/scielo.php?script=sci_arttext\&pid=S010364402018000600606\&lng=en\&tlng=en.

[8] Lasisi TJ, Fasanmade AA. Salivary flow and composition in diabetic and non-diabetic subjects. Niger J Physiol Sci [Internet]. 2012 [cited 2020 Oct 4];27(1):79-82. Available from: https://www.academia.edu/download/56355225/4_Lasisi_and_Fasan made_Niger_J_Physiol_Sci.pdf.

[9] Jeftha A. Xerostomia and salivary flow rates in HIV patients. South African Dent J [Internet]. 2017 [cited 2020 Oct 4];72(2):62-7. Available from: http://www.scielo.org.za/scielo.php?script=sci_arttext\&pid=S001185162017000200004.

[10] Benn AML, Broadbent JM, Thomson WM. Occurrence and impact of xerostomia among dentate adult New Zealanders: findings from a national survey. Aust Dent J. 2015 Sep;60(3):362-7. 
[11] Johansson AK, Johansson A, Unell L, Ekbäck G, Ordell S, Carlsson GE. Self-reported dry mouth in Swedish population samples aged 50 , 65 and 75 years. Vol. 29, Gerodontology. 2012.

[12] Rad M, Kakoie S, Niliye Brojeni F, Pourdamghan N. Effect of Long term Smoking on Whole-mouth Salivary Flow Rate and Oral Health. J Dent Res Dent Clin Dent Prospects [Internet]. 2010 [cited 2019 Jun 30];4(4):110-4. Available from: http://www.ncbi.nlm.nih.gov/pubmed/23346336.

[13] Petrušić N, Posavac M, Sabol I, Mravak-Stipetić M. The Effect of Tobacco Smoking on Salivation. Acta Stomatol Croat [Internet]. 2015 Dec [cited 2019 Jun 30];49(4):309-15. Available from: http://www.ncbi.nlm.nih.gov/pubmed/27688415.

[14] Minja IK, Makoye MN, Lyimo AJ. Prevalence and Assessment of Dry Mouth: A Study among Selected Group of Elderly Patients in Dar es Salaam. EC Dent Sci [Internet]. 2019 [cited 2020 Oct 4];18:392-400. Available

from: https://www.researchgate.net/profile/Irene_Minja/publication/34186 9391_EC_DENTAL_SCIENCE_Research_Article_Prevalence_and Assessment_of_Dry_Mouth_A_Study_among_Selected_Group_of_ Elderly_Patients_in_Dar_es_Salaam/links/5ed78eb892851c9c5e74d 343/EC-DENTAL-SCI.

[15] Henriksen BM, Ambjørnsen E, Axéll TE. Evaluation of a mucosalplaque index (MPS) designed to assess oral care in groups of elderly. Spec Care Dentist. 1999 Jan;19(4):154-7.

[16] Carda C, Mosquera-Lloreda N, Salom L, Gomez De Ferraris ME, Peydró A. A structural and functional salivary disorders in type 2 diabetic patients. Med Oral Patol Oral Cir Bucal. 2006;11(4):209-14.

[17] Quandt SA, Savoca MR, Leng X, Chen H, Bell RA, Gilbert GH, et al Dry mouth and dietary quality inolder adults in north Carolina. J Am Geriatr Soc. 2011 Mar;59(3):439-45.

[18] Ship JA, Pillemer SR, Baum BJ. Xerostomia and the Geriatric Patient. J Am Geriatr Soc. 2002 Mar;50(3):535-43.

[19] Khan GJ, Javed M, Ishaq M. Effect of smoking on salivary flow rate. Gomal J Med Sci [Internet]. 2010 [cited 2020 Oct 4];8(2):(2) 221-224. Available

from: https://scholar.google.com/scholar?hl=en\&as_sdt=0\%2C5\&q=Effect +of+smoking+on+salivary+flow+rate+GJ+Khan $\% 2 \mathrm{C}+\mathrm{M}+\mathrm{Javed} \% 2$ $\mathrm{C}+\mathrm{M}+$ Ishaq+-+Gomal+Journal+of+Medical+Sciences\%2C+2010++ gjms.com.pk\&btnG=.

[20] Dyasanoor S, Saddu SC. Association of xerostomia and assessment of salivary flow using modified schirmer test among smokers and healthy individuals: A preliminutesary study. J Clin Diagnostic Res. 2014;8(1):211-3.

[21] Bouquot D, Schroeder K. Oral effects of tobacco abuse. J Am Dent Inst Cont Educ. 1992;43:3-17.

[22] Thomson WM. Issues in the epidemiological investigation of dry mouth. Gerodontology. 2005;22(2):65-76.

[23] Marchini L, Vieira PC, Bossan TP, Montenegro FL, Cunha VP. Selfreported oral hygiene habits among institutionalised elderly and their relationship to the condition of oral tissues in Taubat??, Brazil. Gerodontology. 2006 Mar;23(1):33-7.

[24] Kida IA, Astrøm AN, Strand G V, Masalu JR. Clinical and sociobehavioral correlates of tooth loss: a study of older adults in Tanzania. BMC Oral Health. 2006 Jan;6:5.

[25] Gupta A, Epstein J, Sroussi H. Hyposalivation in elderly patients. J Can Dent Assoc (Tor) [Internet]. 2006 [cited 2020 Oct 4]; 72:9. Available from: https://scholar.google.com/scholar?hl=en\&as_sdt=0\%2C5\&q=Gupta $\% 2 \mathrm{C}+\mathrm{A} . \% 2 \mathrm{C}+\mathrm{Epstein} \% 2 \mathrm{C}+\mathrm{J}+\mathrm{B} . \% 2 \mathrm{C}+\% 26+$ Sroussi $\% 2 \mathrm{C}+\mathrm{H} .+\% 28$ $2006 \% 29 .+$ Hyposalivation+in+elderly+patients. +Journal+of+the+Ca nadian+Dental+Association $\% 2 \mathrm{C}+72 \% 289 \% 29 . \& \mathrm{btnG}=$.

[26] Mosha H, Senkoro A, Masalu J, Kahabuka F, Mandari G, Mabelya L, et al. Oral health status and treatment needs among Tanzanians of different age groups. Tanzania Dent J [Internet]. 2005 [cited 2020 Oct 4];12(1):18-27. Available from: https://www.ajol.info/index.php/tdj/article/view/37541.

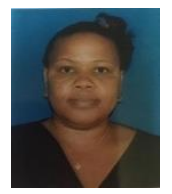

MDent-Anna Joseph Lyimo was born in Moshi, Kilimanjaro, Tanzania. She graduated in Doctor of Dental Surgery from Muhimbili University of Health and Allied Science (2008). In 2017 she graduated a Masters in Dentistry in Restorative degree - MDent Restorative Dentistry at Muhimbili University of Health and Allied Sciences, DarEs-Salaam Tanzania. Her areas of interest are Cosmetic dentistry, Prothodontics, Endodontics, Periodontics and Conservative dentistry.

Currently she is a clinical specialist at the Muhimbili National Hospital

Dar- Es - Salaam Tanzania.

Her recent publication is:
1. Minja, I. K., Ndalahwa, M. M., \& Lyimo, A. J. (2019). Prevalence and Assessment of Dry Mouth: A Study among Selected Group of Elderly Patients in Dar es Salaam.

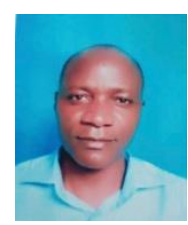

Mdent Makoye Mang'oma Ndalahwa was born in Simiyu, Kalemela, Tanzania. He graduated in Doctor of Dental Surgery from University of Dar Es Salaam (2004). He pursued a Master in Dentistry in Restorative Dentistry degree - MDent Restorative Dentistry (2014) at Muhimbili University of Health and Allied Sciences (MUHAS) Dar Es Salaam, Tanzania. He is involved in areas of Endodontics, Conservative Dentistry, Cosmetic Dentistry and Biomaterials. Currently, he is a Lecturer and Head of Department, Restorative Dentistry, School of Dentistry at Muhimbili University of Health and Allied Sciences (MUHAS), Dar Es Salaam, Tanzania. His current publication is: listed below:

1. Minja, I. K., Ndalahwa, M. M., \& Lyimo, A. J. (2019). Prevalence and Assessment of Dry Mouth: A Study among Selected Group of Elderly Patients in Dar es Salaam.

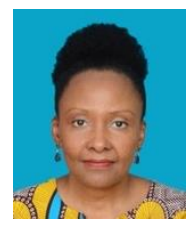

Ph.D. Irene Kida Minja was born in Dar es Salaam, Tanzania. Graduated in DDS (1993), University of Dar es Salaam, Dar es salaam, Tanzania, MPhil-Dentistry (1998) and PhD. (2007) in Dentistry from University of Bergen, Norway. She is a Senior Lecturer in the Department of Restorative Dentistry, Muhimbili University of Health and Allied Sciences (MUHAS), teaching Gerodontology, Dental Biomaterials, and Educational Principals and Practices for the Health Sciences Professionals.

She is currently a coordinator of Health Profession Educators Group (HPEGs) for Faculty Development; and skills development coordinator for the Sickle Pan African Research Consortium (SPARCO)-MUHAS. Some of her publications are:

1. Perea-Lowery, L., Minja, I. K., Lassila, L., Ramakrishnaiah, R., \& Vallittu, P. K. (2020). Assessment of CAD-CAM polymers for digitally fabricated complete dentures. The Journal of Prosthetic Dentistry.

2. Minja, I. K., Lowery Wilson, M., Shaikh, M. A., \& Perea-Lowery, L. (2019). Head and neck trauma in a rapidly growing African metropolis: a two-year audit of hospital admissions. International journal of environmental research and public health, 16(24), 4930.

3. Minja, I. K., \& Kahabuka, F. K. (2019). Dental Anxiety and Its Consequences to Oral Health Care Attendance and Delivery. In Anxiety Disorders-From Childhood to Adulthood. IntechOpen. 